Tatjana Timotijević,

PMF Kragujevac

Ana Kaplarević-Mališić,

PMF Kragujevac

Zoran Ognjanović,

Matematički institut, SANU Beograd

zorano@turing.mi.sanu.ac.rs

UDK 004.822

Izvorni naučni članak

\title{
DESKRIPTIVNE LOGIKE I \\ ONTOLOGIJE - OSNOVA ZA WEB BUDUĆNOSTI
}

\begin{abstract}
APSTRAKT
Ontologije su kao tema istraživanja iz oblasti veštačke inteligencije postale popularne početkom devedesetih godina. Nešto kasnije ideja ontologija je počela široko da se koristi u oblastima kao što su inteligentni informacioni sistemi, pretraga podataka na Internetu i knowledge management. U ovom radu dato je objašnjenje pojma ontologije i njegove uloge u Semantičkom Web-u. Takođe su dati osnovni pojmovi deskriptivnih logika, kao ontoloških jezika. U nastavku je dat kratak pregled primena ontologija, naročito u svrhu deljenog razumevanja znanja iz oblasti arheologije.
\end{abstract}

KlJuČne ReČı: Veštačka inteligenciJa, Deljeno razumevanje, Opisne logike, SemantičKi Web

\section{UVOD}

Da bi ljudi, organizacije pa i softverski sistemi mogli da funkcionišu u sistemu u kome se nalaze, konstantno ili bar povremeno, moraju komunicirati jedni sa drugima i među sobom. Međutim, zbog različitih potreba i polaznih osnova mogu imati i različite tačke posmatranja problema ili zadatka koji treba da obave. Svako od njih može koristiti drugačiji žargon/jezik, a mogu se javiti i razlike u viđenjima pojmova, struktura i metoda. Posledica nedostatka deljenog razumevanja (predstave o temi) je loša komunikacija među njima [Gruninger i dr 1996]. U kontekstu razvoja IT sistema, posledice su teškoće u identifikovanju zahteva jednog sistema prema drugom. Razlike u metodima modelovanja, konceptima, jezicima i softverskim alatima ograničavaju in- teroperabilnost i mogućnost upotrebe i deljenja već napravljenog (re-use i sharing). Krajnja posledica jeste beskonačni ciklus otkrivanja već otkrivenog, tj. pravljenja već napravljenog. Rešenje problema jeste smanjenje ili eliminacija pojmovnih i terminoloških konfuzija, tj. izgradnje deljenog (obostranog) razumevanja. Sa aspekta IT sistema deljeno razumevanje, između ostalog, omogućava:

re-usability - tj. daje osnovu za formalno kodiranje važnih entiteta, atributa, procesa i njihovih međusobnih odnosa u domenu interesovanja, tako da formalna reprezentacija može postati re-usable i/ili deljena komponenta sistema,

pouzdanost - formalna reprezentacija čini mogućom automatizaciju provere konzistentnosti znanja/informacija pa je time i softver pouzdaniji, specifikaciju - tj. deljeno razumevanje 
može pomoći u procesu identifikovanja zahteva i specifikacije IT sistema; ovo je naročito bitno kada zahtevi podrazumevaju korišćenje različitih terminologija istog domena.

Pojam koji se danas koristi kao sinonim deljenom razumevanju nekog domena intersovanja jeste ontologija. Ona predstavlja sliku pogleda na svet ili nekog njegovog dela i podrazumeva skup pojmova, njihovih definicija i definicija njihovih odnosa. Ova slika može biti implicitna, tj. u nečijoj glavi, ali i eksplicitna, tj. "materijalizovana". I pored mogućnosti da slika, pa i ontologija, može biti implicitna ipak se pod tim pojmom, u literaturi ograničenoj na računarske nauke (pre svega veštačku inteligenciju) podrazumeva eksplicitna predstava.

Predstavljanje znanja ontologijama postaje sve popularnije u svim oblastima informacionih tehnologija, npr. knowledge management, integracija informacija, kooperativnim informacionim sistemima, pretragama i e-commerce-u. Jedna od oblasti u kojima su ontologije zauzele centralno mesto jeste Semantički Web.

Semantički Web je proširenje postojećeg hypertext Web-a (upotebom određenih standarda, markup jezika i alata za obradu). Njegova svrha je kreiranje univerzalnog medijuma za razmenu informacija u opisima koji poseduju semantiku razumljivu računaru. Ono čime se WWW konzorcijum, kao matična organizacija koja postavlja Web standarde, bavi jeste definisanje standarda jezika za opisivanje podataka sa njihovim značenjima. Centralnu ulogu u složenoj strukturi Semantičkog Web-a (slika 1.1) igraju ontološki jezici, tj. jezici za predstavljanje ontologija.

Kako god da je rešen način zapisivanja ontologija, rezonovanje o njima predstavlja

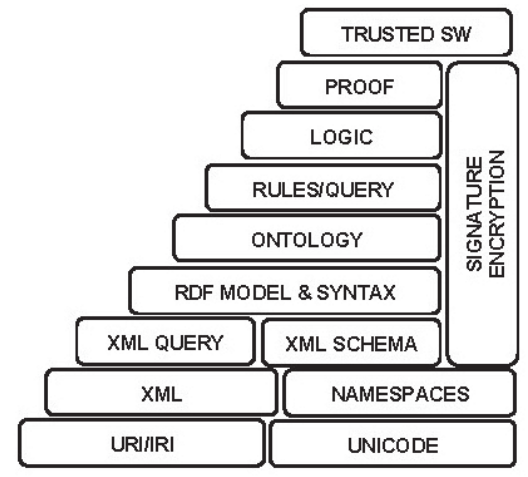

Slika1.1 Struktura Semantičkog Web-a sledeću stepenicu u potpunoj realizaciji Web-a budućnosti. U rezonovanju posebnu ulogu imaju deskriptivne logike.

U narednoj sekciji (sekcija 2.) biće dato detaljnije objašnjenje pojma ontologija. U sekciji 3. biće dat kratak opis deskriptivnih logika kao jezika za predstavljanje i rezonovanje u ontologijama, zatim će u sekciji 4. biti dati primeri upotrebe ontologija konkretnih domena znanja sa posebnim osvrtom na domen arheoloških istraživanja.

\section{ONTOLOGIJA}

Kompleksnost, pa i uspešnost, bilo kog IT sistema koji implicitno ili eksplicitno za svoje funkcionisanje koristi neku bazu znanja (ima bar ograničenu svest o značenju informacija koje obrađuje) u velikoj meri zavisi od načina reprezentacije (predstavljanja) znanja - KR (Knowledge Representation). Formalno predstavljeno znanje koje takvi, tzv. KB (Knowledge Based) sistemi koriste predstavlja konceptualizaciju domena interesovanja, ${ }^{1}$ tj. uočavanje/izdvajanje objekata, pojmova i drugih entiteta kao i relacija koje ih vezuju. Konceptualizacija je apstraktan, pojednostavljen pogled na svet koji želimo da predstavimo. Svaki KB sistem počiva na nekoj konceptualizaciji, eksplicitnoj ili implicitnoj. Eksplicitna specifikacija konceptualizacije se u oblastima računarskih nauka naziva ontologijom.

Ontologija definiše termine koji se koriste za opisivanje i predstavljanje znanja. Njih mogu koristiti ljudi, baze podataka i aplikacije kojima je potrebno da podele informacije iz nekog domena. Ontologija podrazumeva computer-usable definicije pojmova i relacija među njima. Od toga koliko je detaljno izvedena specifikacija zavisi izražajnost same ontologije. Semantički bogatije ontologije podrazumevaju veću izražajnost ,alata"/jezika kojima se one opisuju, tj. predstavljaju u obliku obradivom od strane računara, tj. aplikacija.

Termin ontologija u računarskim naukama je pozajmljen iz filozofije. Pojam ontologija ima dugu istoriju u filozofiji. U filozofiji ona predstavlja „teoriju ili proučavanje postojanja onakvog kakvo jeste". ${ }^{2}$ Dakle, u filozofiji ona se odnosi na proučavanje samog postojanja i svega što postoji.

1 Gruber 1993

2 „Encyclopedia Britannica” - Britannica 2002 
$\mathrm{U} \mathrm{KB}$ sistemima ono što postoji prevedeno je $\mathrm{u}$ ono što se može predstaviti/reprezentovati. Jedna od najčešće citiranih definicija ontologija (u računarskim naukama) jeste: „Ontologija je eksplicitna specifikacija konceptualizacije"3 koja je bez direktnog navođenja već objašnjena u prvom delu ove sekcije. Drugu, manje formalnu je dao Tim Berners-Lee ${ }^{4}$ „ontologija je dokument ili fajl kojim se formalno definišu termini i relacije između njih". Dakle, sve što predstavlja eksplicitnu specifikaciju uočenih objekata, klasa i njihovih relacija manje ili više detaljno (upotrebom manje ili više izražajnih jezika) se smatra ontologijom.

Nije realno očekivati da će sve aplikacije koje koriste ontologije koristiti istu ontologiju, pa ni isti jezik za opisivanje ontologija. Dakle, sa jedne strane postoji heteroganost zapisa, kao i heterogenost ,viđenja” istih domena znanja. Sa druge strane sistemi koji u svojoj stukturi poseduju neku bazu znanja, su u osnovi skupi u svim fazama svog životnog veka (izgradnja, testiranje, održavanje), pa je deljenje već postojećih ontologija poželjno. $\mathrm{Na}$ osnovu navedenog očigledno je zašto postoji potreba da znanje i informacije predstavljene ontologijama budu deljivi. Tako se u literaturi sve češće sreće proširena definicija [Studer i dr. 1998] u odnosu na datu ${ }^{5}$ u kojoj se kaže da je ontologija formalna, eksplicitna specifikacija deljene konceptualizacije.

Ovom definicijom pojam ontologija je sužen na mašinski obradive zapise ontologija koje su deljive, tj. opisuju znanje koje ne predstavlja subjektivno viđenje domena niti je ono privatno već prihvaćeno od strane ,grupe” ljudi. Naime cilj je stvaranje ontologija kojima se "hvata” domensko znanje koje će biti nezavisno od zadataka za čije je ispunjavanje to znanje potrebno.

Upotreba ontologija zahteva dobro definisan jezik za njihovo opisivanje. Od izražajnosti samog jezika zavisi i preciznost opisa, pa tako opisane ontologije mogu biti ${ }^{6}$ :

$u$ velikoj meri neformalne: izražene neprecizno u prirodnom jeziku,

polu-neformalne: izražene u ograničenoj i strukturnoj formi prirodnog jezika, što značajno povećava jasnoću i redukuje dvosmislenost,

3 Gruber 1993

4 The Semantic Web, Scientific American, May 17, 2001

5 Gruber 1993

6 Gruninger i dr 1996 polu-formalne: izražene u veštački formalno definisanom jeziku, kao što je Ontolingua ([Ontolingua]), verzija jezika iz projekta Enterprise Ontology,

strogo formalne: detaljno definisani pojmovi sa formalnom semantikom, teoremama i dokazima, sa osobinama kao što su zasnovanost i kompletnost.

„Zapisane” ontologije imaju ograničenu upotrebljivost, ako nisu podržane alatima za rezonovanje nad njima. Rezonovanje je bitno: u obezbeđivanju kvaliteta ontologija koje se kreiraju, za upotrebu informacija opisanih ontologijama. Ono se može koristiti u različitim fazama životnog ciklusa ontologija. Za vreme kreiranja može se koristiti za proveru da li su uvedeni pojmovi kontradiktorni, kao i za izvođenje novih veza između njih. Najčešće se koristi za izvođenje hijerarhije pojmova, tj. uređivanje pojmova prema njihovoj pripadnosti (koji je pojam podpojam drugog pojma). Informacije o tome koji je pojam specijalizacija kog, a koji su pojmovi sinonimi se mogu koristiti pri proveri da li definicije pojmova uvedene u ontologiji daju željene rezultate ili ne. Ove informacije se takođe koriste i u fazi eksploatacije ontologija.

Kakve vrste zaključaka se mogu izvoditi, a, naravno, i detaljnost opisa ontologije zavise od, kako je već rečeno, izražajnosti jezika opisivanja. Strogo formalne ontologije su, svakako, najbogatije informacijama, pa i alati koji sa njima mogu raditi nude najbogatiji spektar mogućnosti za njihovu upotrebu. Jezici formalnih ontologija moraju imati dobro definisanu semantiku i moćne alate za rezonovanje/zaključivanje. U takve jezike spadaju deskriptivne logike. Pokazalo se da zbog svoje prirode u potpunosti odgovaraju opisivanju ontologija sa jedne strane, dok sa druge nude formalno zasnovane mehanizme zaključivanja.

\section{DESKRIPTIVNA LOGIKA}

Deskriptivna logika (DL) je najčešće korišćeno ime za familiju formalizama za predstavljanje znanja. Njima se predstavlja znanje koje se primenjuje na određeni domen i definišu relevantni pojmovi domena, tj. terminologija. Ime deskriptivna logika je sasvim opravdano zato što ova karakterizacija sadrži logički zasnovanu se- 
mantiku i podržava šablone za zaključivanje, koji se javljaju u mnogim primenama inteligentnih sistema za obradu informacija. Pošto baza znanja treba korisniku da ponudi traženi odgovor u prihvatljivom vremenu, istraživači se bave procedurama odlučivanja koje uvek moraju da se zaustave, što nije slučaj kod svih formalnih sistema.

Sledeće tri ideje su pomogle razvoju DL-a:

Osnovni gradivni elementi jednog DL sistema su atomski pojmovi, atomske uloge $\mathrm{i}$ individue.

Izražajna moć jezika je ograničena na mali skup operatora za konstruisanje složenih pojmova i uloga.

Implicitno znanje o pojmovima $\mathrm{i}$ individuama se može izvesti pomoću procedura za zaključivanje.

Sistem baze znanja zasnovan na DL-u obuhvata dve komponente: TBox i ABox. TBox predstavlja rečnik domena - terminologiju, dok ABox sadrži tvrđenja o individuama u terminima iz rečnika. Tipične procedure za zaključivanje se odnose na proveru da li neka terminologija nije kontradiktorna, da li je opis nekog pojma opštiji od drugog, da li su tvrđenja u ABox-u dosledna. Testiranjem relacija između pojmova, pojmovi definisani u TBox-u se mogu organizovati u hijerarhijsku strukturu prema opštosti.

\section{OSNOVNI JEZIK ZA OPIS POJMOVA}

Osnovni opisi su atomski pojmovi i atomske uloge. Kompleksni pojmovi se grade od njih induktivno, pomoću konstruktora pojmova. U daljem tekstu će u abstraktnim opisima pojmova slova $A$ i $B$ biti korišćena za atomske pojmove, slovo $R$ za atomske uloge i slova $C$ i $D$ za opise pojmova. Osnovni jezik je $A L$ (attributive language) i opis ojmova se u ovom jeziku formira na osnovu sledećeg sintaksnog pravila:

Primer 3.1. Neka su Person i Female atomski pojmovi. Tada su Person i Female i Person $\mathrm{A} \neg$ Female pojmovi koji opisuju

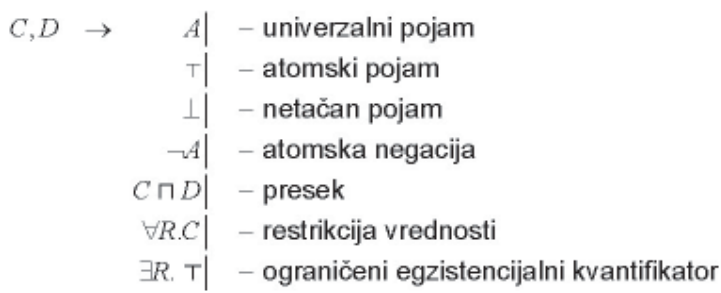

osobe koje su žene i osobe koje nisu žene. Ako je haschild atomska uloga, tada pojmovi Personithaschild.T, Personit hasChild.Female i Personה $\forall$ haschild. $\perp$ označavaju redom osobe koje imaju decu, one osobe čija su sva deca ženska i osobe koje nemaju decu.

Osnovni AL jezik se proširuje dodavanjem novih konstruktora:

unija (U ) koja se zapisuje sa $C+D$

potpun egzistencijalni kvatnifikator $(\mathrm{E})$

koji se zapisuje sa $\exists R . C$

ograničenje kardinalnosti $(\mathrm{N})$ koje sa zapisuje sa $\mathrm{b} n R$ ili $\mathrm{r} n R$, gde je $n$ nenegativan ceo broj

negacija pojma (C) koja se zapisuje sa $\neg C$, gde je $C$ opis pojma

Primer 3.2. Dodatim konstruktorima se mogu opisati osobe koje imaju ne više od jednog deteta ili imaju najmanje 3 deteta od kojih je jedno žensko

Person * (blhasChild + (r 3hasChild* ᄏhasChild.Female $)$ )

Proširivanjem $A L$ jezika nekim skupom konstruktora dobija se konkretan $A L$ jezik čije je ime zapis oblika $A L[U][E][N][C]$, gde svako slovo predstavlja odgovarajući konstruktor.

\subsection{Terminologija (TBox)}

Terminologija ili TBox predstavlja konačan skup definicija oblika

$$
A \equiv C \text {, }
$$

gde je $A$ ime pojma koji se definiše, a $C$ opis pojma. Osim definicija u TBox-u mogu da se dozvole i inkluzije oblika

\section{$A \mathrm{mC}$}

kojima se definiše da je atomski pojam $A$ podpojam pojma $C$. Terminologija $\mathrm{T}$ sadrži ciklus ukoliko se pri definiciji nekog pojma koristi taj isti pojam. Takve terminologije se nazivaju ciklične. Ukoliko u terminologiji $\mathrm{T}$ ne postoji ciklus, tada je terminologija aciklična (Slika 3.1).

Primer 3.3. Koristeći ciklično definisanje pojmova moguće je definisati pojam koji opisuje čoveka koji ima samo muško potomstvo

Momo $\equiv$ Man * $\forall$ hasChild.Momo

\subsection{Tvrđenja o individuama (ABox)}

U ABox-u se uvode individue zadavanjem imena i tvrđenja o osobinama tih individua. 


$\begin{aligned} \text { Woman } & \equiv \text { Person* Female } \\ \text { Man } & \equiv \text { Person* } \neg \text { Women } \\ \text { Mother } & \equiv \text { Woman* } \text { hasChild.Person } \\ \text { Father } & \equiv \text { Man* } \exists \text { hasChild.Person } \\ \text { Parent } & \equiv \text { Father }+ \text { Mother } \\ \text { Grandmother } & \equiv \text { Mother* } \exists \text { hasChild.Parent } \\ \text { MotherWithManyChildren } & \equiv \text { Mother* } \text { 3hasChild } \\ \text { MotherWithoutDaughter } & \equiv \text { Mother* } \forall \text { hasChild. } \neg \text { Women }\end{aligned}$

Slika 3.1. Primer terminologije (TBox) rodbinskih veza

U abstraktnim opisima individue će biti označene slovima $a, b, c$. Uz pomoć pojmova $C$ i uloga $R$ zadaju se dva osnovna tipa tvrđenja:

$C(a)$ i $R(b, c)$.

Prva vrsta tvrđenja označava da individua $a$ pripada pojmu $C$ - tvrđenje o pojmu, dok druga vrsta označava da je $c$ par za $b$ u ulozi (relaciji) $R$-tvrđenja o ulogama.

Primer 3.4. Na osnovu TBox-a rodbinski veza (Slika 3.1), odgovarajući ABox može da sadrži tvrđenja

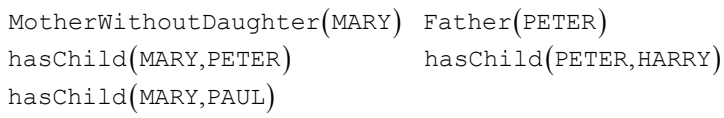

\section{Slika 3.2. Primer ABox-a rodbinskih veza}

\subsection{Procedure zaključivanja}

Pri modelovanju domena baze znanja konstruiše se terminologija $\mathrm{T}$ definisanjem novih pojmova. Pri ovome je bitno proveravati:

da li pojmovi koji se definišu imaju smisla ili su kontradiktorni sa već definisanim pojmovima, tj. da li je pojam zadovoljiv ili ne;

da li je neki pojam opštiji od drugog u odnosu na definisanu teminologiju, tj. da li je pojam obuhvaćen drugim pojmom, što se zapisuje sa $C \mathrm{~m}_{\mathrm{T}} D$;

da li su neka dva pojma ekvivalentna u odnosu na terminologiju $\mathrm{T}\left(C \equiv_{\mathrm{T}} D\right)$;

da li su neka dva pojma različita, tj. disjunktna u odnosu na terminologiju $\mathrm{T}$.

Primer 3.5. Za terminologiju rodbinskih veza (Slika 3.1) može se ispitivati da li je ispunjeno

Grandmother mWomen

ili da li su pojam

MotherWithoutHelpinaHouse $\equiv \neg$ Man * Parent * $\forall$ hasChild. $\neg$ Women i pojam MotherWithoutDaughter iz TBox-a ekvivalentni.

Osnovni mehanizam za zaključivanje je provera obuhvaćenosti pojmova, a kako svi opisni jezici implementirani u DL sisteme sadrže operator preseka * i netačan pojam, tako se na proveru obuhvaćenosti pojma mogu svesti i ostale tri osobine.

Jedan od algoritama za obuhvaćenost pojmova se bazira na sintaksnom poređenju pojmova i može se efikasno primeniti samo na slabo izražajne logike, koje dozvoljavaju samo presek ( $C$ * $D)$, ograničenje vrednosti $(\forall R . C)$, netačan pojam $(\perp)$, atomsku negaciju $(\neg A)$.

Pri uvođenju konstruktora za ograničenje kardinalnosti, tokom provere obuhvaćenosti pojmova mora se voditi računa o prisutnim vezama među ograničenjima kardinalnosti (npr. $\mathrm{r} n R \mathrm{mr} m R$ ako i samo ako je $n \mathrm{r} m$ ). Za sisteme koji sadrže ovaj konstruktor, često se za proveru obuhvaćenosti pojmova koriste algoritmi koji koriste strukture grafova.

Za veće sisteme koji sadrže disjunkciju, potpunu negaciju, potpuni egzistencijalni kvantifikator, kao dosta efikasniji algoritmi pokazali su se tablo bazirani algoritmi. Kod ovih algoritama ispituje se nezadovoljivost pojma, a preostale tri osobine se mogu svesti na nezadovoljivost.

Problem zaključivanja (ispitivanja nezadovoljivosti u ovom slučaju) u odnosu na aciklični TBox se može svesti na zaključivanje u odnosu na prazan TBox. Naime, svaki pojam $A$, koji se javlja u opisu pojma $C$ čija se nezadovoljivost ispituje, se zamenjuje njegovim opisom iz TBoxa, tj. ako se u TBox-u nalazi definicija $A \equiv D$, pojam $A$ se zamenjuje opisom $D$.

Primer 3.6. Pojam MotherWithManyChildren iz TBox-a (Slika 3.1) se razvija u opis

MotherWithManyChildren $\equiv(($ Person * Female $) * \exists$ GasChild.Person $)$ * $r$ haschild

Kako tablo algoritam podrazumeva rad sa $A B o x-o m$, to se isti algoritam primenjuje i pri zaključivanjima vezanim za ABox. Osnovna procedura zaključivanja vezana za ABox A se odnosi na proveru konzistentnosti ABox-a u odnosu na TBox. Slično kao i za pojmove, provera konzistentnosti ABox-a u odnosu na TBox 
se može svesti na proveru konzistentnosti ABox-a u odnosu na prazan TBox, tj. proveru konzistentnosti razvijenog ABox-a. Drugi problem je provera da li se neko tvrđenje o pojmu $C(a)$ može izvesti iz ABox-a, što se svodi na proveru konzistentnosi skupa tvrđenja $\mathrm{A} \cup\{\neg C(a)\}$.

Ako se baza znanja opisana pomoću nekog DL jezika koristi za čuvanje informacija o individuama, tada se kao poseban poseban proces zaključivanja posmatra problem pronalaženja svih individua koje su primerci nekog pojma, tj. opisni jezik se koristi za postavljanje upita. Neoptimizovani algoritam za upit za pronalaženje se može realizovati testiranjem svake individue koja se javlja u ABox-u.

Primer 3.7. Za posmatrani primer rodbinskih veza možda je potrebno dobiti spisak svih roditelja koji imaju najmanje dvoje dece radi oslobađanja od poreza.

\section{IZRAŽAJNE DESKRIPTIVNE LOGIKE}

Veća izražajnost jezika deskriptivne logike se postiže dodavanjem novih konstruktora, pre svega konstruktora uloga. Pri izgradnji nekog DL sistema za uloge $R$ i $S$ i pojam $C$ moguće je koristiti sledeće konstruktore uloga: presek $R * S$

unija $-R+S$; komplement $-\neg R$; kompozicija $-R \circ S$; tranzitivno zatvorenje $-R^{+}$; inverzija $R^{-}$; jedinična uloga $-i d(C)$ (povezuje pojam sa samim sobom); kvalifikovano ograničenje kardinalnosti-b $n R . C$ i $\mathrm{r} n R . C$.

Najveći problem, pri korišćenju različitih konstruktora uloga pri izgradnji TBox-a i ABoxa, je to što loš izbor kombinacije ovih konstruktora dovodi do neodlučivog sistema, $\mathrm{tj}$. sistema $\mathrm{u}$ kome se procedure za zaključivanje ne zaustavljaju uvek.

Najčešće korišćen jezik za opisivanje konkretnih sistema je SHI Q koji je odlučiv i koji pretstavlja proširenje jezika A L C kome su dodati kvantifikovano ograničenje kardinalnosti, inverzne uloge, i aksiome pripadanja za proizvoljne uloge (aksiome oblika $R \mathrm{~m} S$ za proizvoljne uloge $R$ i $S$ )

\section{PRIMENE ONTOLOGIJA}

U literaturi se može naći veliki broj opisa različitih ontologija i njihovih namena, tj. načina upotrebe. Većina je, u suštini, namenjena nekom vidu višestrukog korišćenja od strane manjeg ili većeg broja aplikacija ili zajednica. Druga, jaka motivacija za upotrebu ontologija jeste integrisanje modela različitih domena u koherentnu mrežu (okvir). Priča o načinima upotrebe se može širiti na različite strane, u ovom radu ćemo se ograničiti na grupu koja se tiče rešavanja problema razumevanja (komunikacije). Naime, vraćamo se na početak - deljeno razumevanje (znanje).

Istraživači iz različitih, ali srodnih oblasti, ne mogu jednostavno i brzo da koriste rezultate drugih. Problem je što oni imaju različitu perspektivu posmatranja problema, i često koriste različite termine za opis u osnovi istih ideja. Rešenje problema je identifikacija zajedničkih ideja u svakom od polja interesovanja, pažljiva tehnička analiza značenja tih koncepata, identifikacija tačnih poklapanja, i naglašavanje ostalih važnih veza između njih. Ovo jedinstveno konceptualno okruženje ima za cilj da dozvoli translaciju između različitih perspektiva.

Ontologije mogu da se koriste za integraciju postojećih skladišta podataka, kako standardizacijom terminologije između različitih korisnika i skladišta, tako i obezbeđivanjem semantičkih osnova za translatore između različitih korisnika.

$\mathrm{Da}$ bi pomogle interoperabilnost, ontologije se mogu koristiti za podršku translacije između jezika i reprezentacija. Jedan od pristupa je realizacija jedinstvenog translatora za svaka dva učesnika u razmeni (Slika 4.1a). Korišćenjem ontologija kao inter-lingua za podršku translacije, može se redukovati broj, pošto se u tom slučaju zahteva samo postojanje translatora od lokalne ontologije u ontologiju za razmenu (Slika 4.1b).

\section{Primene ontologiJa u Oblasti ARHEOLOGIJE \\ Realizacija ideje deljenog razumevanja deluje interesantno i istraživačima iz oblasti društvenih i humanističkih nauka, koje su po svojoj prirodi bogate velikom količinom infor- macija koje bi bilo dobro razmenjivati bi mogle imati velike koristi od realizacije ove ideje. $\mathrm{Na}$ primer, za razliku od matematike u kojoj je gov-}


orni jezik istraživača manje bitan u njihovom međusobnom razumevanju i u kojoj su pojmovi strogo i opšteprihvaćeno stuktuirani i definisani, "nepoklapanje" pojmova kao posledica korišćenja govornih jezika (koji se po bogatstvu opisa razlikuju) je često u društvenim naukama.

Što se arheoloških istraživanja tiče pokušaji definisanja globalne ontologije vezane za deo ili kompletnu oblast arheologije su već napravljeni, ${ }^{7}$ ali još uvek ne postoji opšteprihvaćena specifikacija i na osnovu nje realizovana ontologija. Značaj njene realizacije je višestruk. Kao prvo, predstavljala bi među jezik (inter-lingua) sistema koji se tiču arheologije. Kao drugo njena specifikacija na jezicima Semantičkog Web-a bi omogućila dobijanje informacija iz velikog broja već postojećih arheoloških digitalnih biblioteka (sa jedne strane digitalne biblioteke već poseduju svoje zapise dostupne u nekom Web formatu, kao što su html, XML i sl., a sa druge strane Web ontološki jezici moraju biti uskladivi sa već postojećim i upotrebljenim Web standardima) kao i drugih izvora iz Web prostora.

\section{ZAKLJUČAK}

Ontologija, kao sinonim deljenom razumevanju, predstavlja polaznu tačku u povezivanju heterogenih sistema koji u sebi nose velike količine informacija. Njihova specifikacija u jezicima Semantičkog Web-a bi donela nezavisan okvir prema kome bi svaki od sistema mogao da napravi svoj "most". Samo povezivanje ne bi imalo poseban značaj da Web ontološki jezici nisu namenjeni opisivanju značenja informacija, tj. opisivanju terminologije i odnosa među pojmovima definisanim ontologijom. Dakle, ključnu ulogu ima semantika koju ontologije nose. Sama specifikacija značenja pojmova nije dovoljna ako ne postoji mehanizam zaključivanja o pojmovima, njihovim odnosima i odnosima primeraka nekog pojma. Dobar okvir za opisivanje i rezonovanje daju deskriptivne logike.

U oblasti arheologije definisanje opšte ontologije kojom bi bili obuhvaćeni pojmovi relevantni za ovu oblast predstavlja značajan korak u pokušaju integracije velikog broja raznovrsnih

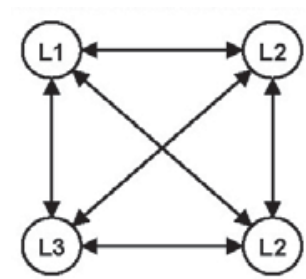

(a)

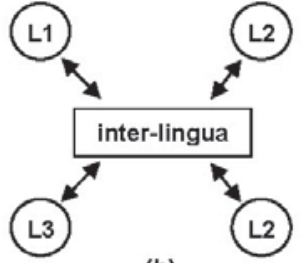

(b)
Slika 4.1. Ontologija kao inter-lingua

izvora informacija i podataka. Ovaj rad predstavlja početak istraživanja na tu temu kod nas i nastavak dugogodišnje saradnje Matematičkog i Arheološkog instituta Srpske akademije nauka i umetnosti u Beogradu, koja je započeta izradom ekpertnog sistema PANDORA. ${ }^{8}$

\section{LITERATURA}

\section{Baader i dr 2002}

F. Baader, D. L. McGuinnes, D. Nardi, P. F. Patel-Schneider, The Description Logic Handbook: Theory, Implementation and Applications, Cambridge University Press, 2002

\section{Chunxia i dr. 2002}

Chunxia Z., Cungen C., Fang G., Jinxin S., A Domain-Specific Formal Ontology for Archaeological Knowledge Sharing and Reusing, PAKM 2002, LNAI 2569, pp. 213-225, 2002.

\section{Gruber 1993}

Gruber, T. R. A, Translation Approach to Portable Ontology Specifications, Technical Report, Academic Press, Stanford, 1993

\section{Gruninger i dr 1996}

Uschold M., Gruninger M., Ontologies: Principles, Methods and Applications, Technical report, AIAI-TR-191, February 1996, University of Edinburg, also in Knowledge Engineering Review, Vol. 11, No. 2, June 1996.

\section{ISO 21127:2006}

ISO 21127:2006, Information and documentation - A reference ontology for the interchange of cultural heritage information

8 Jocković i dr 1997 
Jocković i dr 1997

Jocković M., Ognjanović Z., Stanovski S., Veštačka inteligencija - inteligentne mašine i sistemi, Krug, Beograd, 1997

\section{Ontolingua}

http://ontolog.cim3.net/cgi-bin/

\section{Staab i dr 2004}

Staab S., Studer R., Handbook on Ontologies, Springer-Verlag, Berlin, 2004

Studer i dr. 1998

R. Studer, V.R. Benjamins, D. Fensel, Knowledge Engineering: Principles and Methods, Data Knowl. Eng. 25(1-2): 161-197 (1998)

\section{DESCRIPTIVE LOGICS AND ONTOLOGIES - BASE FOR THE} FUTURE WEB

Since the beginning of the nineties ontology have become a popular research topic investigated by several Artificial Intelligence research communities. More recently, the notion of ontology is also becoming widespread in fields such as intelligent information integration, information retrieval on the Internet, and knowledge management. In this paper we give an explanation of the notion of an ontology and its role in the Semantic Web. Since description logics are recognized as good ontology languages, its basic ideas are also given. Later we give a brief overview of ontology applications, especially in the role of with archaeological knowledge sharing and reusing.

KEY WORDS:

Artificial Intelligence, Knowledge Sharing, Description Logic, Semantic Web 